\title{
Co-crystal of suberic acid and 1,2-bis(4-pyridyl)ethane: a new case of packing polymorphism
}

\author{
Maria A. Susano ${ }^{1}$, Pablo Martín-Ramos ${ }^{1,2}$, Teresa M.R. Maria ${ }^{3}$, Steven Folkersma ${ }^{4}$, Laura C.J. Pereira ${ }^{5}$ \\ and Manuela Ramos Silva ${ }^{1^{*}}$ \\ ${ }^{1}$ CFisUC, Department of Physics, Universidade de Coimbra, Rua Larga, P-3004-516 Coimbra, \\ Portugal. Tel.: +351239410648; Fax:+351239829158; E-mail: manuela@pollux.fis.uc.pt. \\ 2 EPSH, Universidad de Zaragoza, Carretera de Cuarte s/n, 22071, Huesca, Spain. \\ ${ }^{3}$ CQC, Department of Chemistry, Universidade de Coimbra, Rua Larga, P-3004-535 Coimbra, \\ Portugal. \\ ${ }^{4}$ University of Groningen, $9700 \mathrm{AB}$ Groningen, The Netherlands. \\ ${ }^{5} \mathrm{C}^{2} \mathrm{TN}$, IST, Universidade de Lisboa, P-2695-066 Bobadela, Portugal
}

\begin{abstract}
The polymorphic behaviour of a co-crystal composed of neutral suberic acid and 1,2-bis(4pyridyl)ethane is reported. A multidisciplinary approach has been employed, using thermal analysis methods (differential scanning calorimetry and polarised light thermomicroscopy), spectroscopic methods (infrared spectroscopy) and X-ray single crystal and powder diffraction. Two new polymorphs, I and III; have been identified, and for one of them the crystal structure has been elucidated and compared to that of a known polymorph, form II, showing that the assembling of the molecules in chains via $\mathrm{H}$-bonds is a common feature of both polymorphs. Polymorph II, obtained by crystallization from an aqueous or ethanol solution or by grinding, undergoes a solid-solid transition to polymorph I, which melts at $180.5{ }^{\circ} \mathrm{C}$. Upon cooling from the melt, polymorph I is obtained, and a solid-solid transformation also occurs, to polymorph III'. Polymorph III was obtained serendipitously in an attempt to prepare a $\mathrm{Nd}(\mathrm{III})$ complex. The relative stability of the three polymorphic forms was established.
\end{abstract}

Keywords: co-crystal; phase transition; polymorph; thermal analysis; X-ray diffraction.

\section{Introduction}

Polymorphism, many forms, is an area of interest for solid state physicists and chemists, both for experimentalists and theoreticians, as the rapidly growing computer models for predicting crystal structures (e.g., USPEX, CALYPSO, XtalOpt, GULP, GASP) shows [1]. On top of that, the study of polymorphs is of crucial importance to the industry, in particular to the pharmaceutical and food industries. Solid-state property differences resulting from variances in crystal forms can translate into significant differences in properties of pharmaceutical relevance such as the dissolution rate, as shown by studies of phenylbutazone and chloramphenicol $[2,3]$.

The use of molecules in co-crystals or salts was initially thought to prevent the phenomenon of polymorphism, making pharmaceutical production more predictable and controllable, but recent studies have shown that co-crystals can also crystallize in different forms [4]. Some examples come from the food industry, where the use of different polymorphic forms of food additives may result in unsuccessful food processing, as it was shown for the sodium salt of the L-glutamic acid, for which the beta form coagulated into a gel [5].

The different polymorphic forms may arise from different hydrogen bond motifs or synthons and can therefore be classified as synthon polymorphs, a type of polymorphism that is more frequent for molecules with multiple H-bonding capabilities [6]. Polymorphism may also arise from conformational flexibility of one or more of the co-crystal components, with the resulting polymorphs being called conformational polymorphs $[7,8]$. 
Polymorphs can also be classified as packing polymorphs when they differ in the three-dimensional crystal packing, without significant changes in conformation of the molecules $[9,10]$. Finally, the term tautomeric polymorphs is used when the crystal forms contain tautomers (which are able to interconvert in solution or in melt) such as neutral and zwitterionic forms of the same molecule [4].

In the paper presented herein, the polymorphic behaviour of a co-crystal composed of neutral suberic acid, a colourless crystalline solid used in drug syntheses and plastics manufacture, and 1,2-bis(4pyridyl)ethane, a popular linker (Figure 1), was studied through thermoanalytical, vibrational spectroscopy and X-ray diffraction methods. Crystal structure prediction is of fundamental and applied importance, and its successful execution is a persistent problem [11]. Given that the number of reported packing polymorphs is more limited, examples that can provide further insight -such as the one under study- should be useful in computational procedures.<smiles>O=C(O)CCCCCCCC(=O)O</smiles>

suberic acid<smiles>c1cc(CCc2ccncc2)ccn1</smiles>

1,2-bis(4-pyridyl)ethane

Figure 1. Chemical structures of the two starting products.

\section{Materials and methods}

\subsection{Synthesis}

[II] Crystals were grown either from an aqueous solution or from an ethanol solution of suberic acid and 1,2-Bis(4-pyridyl)ethane in a (1:1) molar ratio. Also, a milling methodology was employed (appropriate amounts of both components were weighted and ground in a Retsch (Haan, Germany) MM 400 ball mill, $10 \mathrm{~mL}$ stainless steel grinding jar with two $7 \mathrm{~mm}$ stainless steel balls, at $15 \mathrm{~Hz}$ frequency, for $30 \mathrm{~min}$.), yielding the same structure in powder form.

[III] A solution of neodymium(III) nitrate hexahydrate (99.9\%), suberic acid ( $\geq 98.0 \%)$ and 1,2Bis(4-pyridyl)ethane (99\%) were dissolved in distilled water at acidic $\mathrm{pH}$ and solvent was evaporated at room temperature. The obtained powder was then re-dissolved in N,N-dimethylformamide $(99.8 \%)$ and a non-homogeneous solid mixture was obtained after room temperature evaporation of the solvent.

All reagents were supplied by Sigma-Aldrich and were used without further purification.

\subsection{Structural elucidation}

The crystal structure of polymorph III was elucidated by single crystal X-ray diffraction analysis at room temperature. Powder diffractograms of the samples in function of temperature were obtained using an ENRAF-NONIUS (Enraf-Nonius, Rotterdam, The Netherlands) powder diffractometer (Debye-Scherrer geometry, capillary of $0.3 \mathrm{~mm}$ diameter) equipped with an INEL CPS120 (Inel, Artenay, France) detector and a quartz monochromator selecting the $\mathrm{Cu} \mathrm{K \alpha 1}$ wavelength $(\lambda=1.540598$ $\AA)$. Silicon was utilized as an external calibrant. For temperature control, an Oxford cryostream (Oxford, UK) was used.

For the determination of crystal structure by X-ray diffraction, a crystal of the co-crystal was glued to a glass fibre and mounted on a Bruker (Billerica, MA, USA) APEX II diffractometer. Diffraction data was collected at room temperature 293(2) K using graphite monochromated $\mathrm{MoK} \alpha(\lambda=0.71073$ $\AA$ ). Absorption corrections were made using SADABS [12]. The structure was solved by direct methods using SHELXS-97 [13] and refined anisotropically (non-H atoms) by full-matrix least-squares on $F^{2}$ using the SHELXL-97 program [13]. PLATON [14] was used to analyse the structure. Mercury version 3.1 [15] was used for figure plotting. Atomic coordinates, thermal parameters and bond lengths and angles have been deposited at the Cambridge Crystallographic Data Centre (CCDC). Any request to the CCDC for this material should quote the full literature citation and the reference number CCDC 1544884 . 


\subsection{Physical measurements}

Infrared spectra were recorded with a Thermo Nicolet 380 FT-IR apparatus (Thermo Scientific, Waltham, MA, USA) equipped with a Smart Orbit Diamond ATR accessory. The infrared spectra were collected with $2 \mathrm{~cm}^{-1}$ spectral resolution and 64 scans.

Differential scanning calorimetry (DSC) data were obtained on a DSC7 Perkin Elmer calorimeter (Perkin-Elmer, Waltham, MA, USA), equipped with an intracooler cooling unit at $-10^{\circ} \mathrm{C}$ (ethylene glycol-water, $1: 1 \mathrm{v} / \mathrm{v}$, cooling mixture), with a heating rate $\beta=10^{\circ} \mathrm{C} / \mathrm{min}$, under a $\mathrm{N}_{2}$ purge, $20 \mathrm{~mL} / \mathrm{min}$. Samples were hermetically sealed in aluminium pans, and an empty pan was used as a reference. Temperature calibration was performed with high-grade standards, biphenyl (CRM LGC 2610, $T_{\text {fus }}=$ $\left.(68.93 \pm 0.03){ }^{\circ} \mathrm{C}\right)$ and indium (Perkin-Elmer, $\left.x=99.99 \%, T_{\text {fus }}=156.60^{\circ} \mathrm{C}\right)$, which was also used for enthalpy calibration $\left(\Delta H_{\text {fus }}=(3286 \pm 13) \mathrm{J} \cdot \mathrm{mol}^{-1}\right)[16,17]$.

Optical textural observations were made with a DSC600 hot/cold stage (Linkam Scientific Instruments Ltd., Guildford, Surrey, UK), equipped with a DMRB Leica microscope (Leica Microsystems, Wetzlar, Germany). Images of the samples, observed under polarized light and using wave compensation, were recorded using a Sony CCD-IRIS/RGB video camera at $200 \times$ magnification.

\section{Results and discussion}

\subsection{Structural description}

The title compound contains two half molecules of suberic acid and two half molecules of pyridil ethane in the asymmetric unit cell (Figure 2, Table 1). The molecules of both neutral species are linked in chains through $\mathrm{O}-\mathrm{H} \ldots \mathrm{N}$ hydrogen bonds in a triclinic, centrosymmetric assembling. The chains are all parallel to each other running in the [101] direction.

There is a strong H-bond between the carboxylic group of the acidic molecule and the $\mathrm{N}$ atom of the heteronuclear ring of pyridil-ethane. The same strong bond exists in the reported polymorph by Braga et al. [18], making the molecules assemble in chains (polymorph II). The chains make angles of $\sim 60^{\circ}$ between each other.

Although Braga et al. [18] recognised a weak C-H...O bond between successive molecules in the chain, a re-analysis of their data shows that there is a $\mathrm{C}$ (ring)-H...O bond towards a molecule of a neighbouring chain (with more favouring parameters for a C-H...O interaction). The same inter-chain interaction exists in the title compound; and since molecular conformation is similar for both polymorphic forms, they may classify as packing polymorphs.

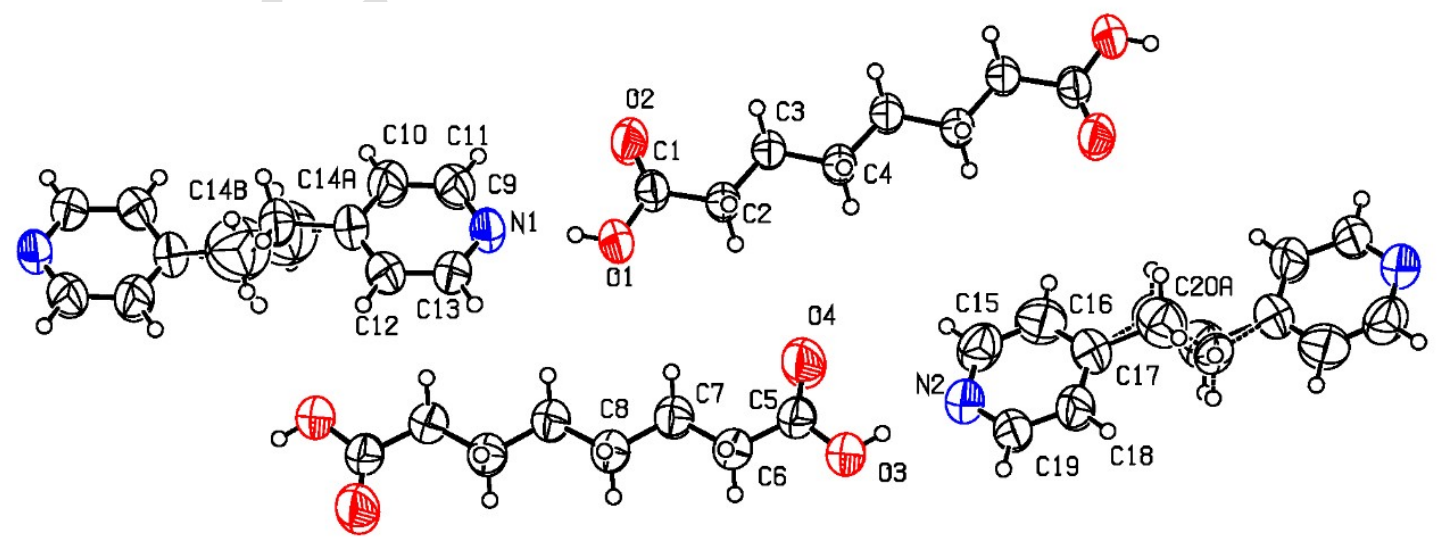

Figure 2. ORTEP diagram of the novel 1,2-bis(4-pyridyl)ethane suberic acid polymorph III. 
Table 1. Crystal data and structure refinement for polymorph III.

\begin{tabular}{|c|c|}
\hline Complex & Polymorph III \\
\hline Empirical formula & $\mathrm{C}_{20} \mathrm{H}_{26} \mathrm{~N}_{2} \mathrm{O}_{4}$ \\
\hline Formula weight & 358.43 \\
\hline Temperature (K) & 293(2) \\
\hline Wavelength $(\AA)$ & 0.71073 \\
\hline Crystal system & triclinic \\
\hline Space group & P-1 \\
\hline$a(\AA)$ & $7.5200(5)$ \\
\hline$b(\AA)$ & $11.0503(7)$ \\
\hline$c(\AA)$ & $13.5028(9)$ \\
\hline$\alpha\left(^{\circ}\right)$ & $107.877(3)$ \\
\hline$\beta\left(^{\circ}\right)$ & $96.537(3)$ \\
\hline$\gamma\left({ }^{\circ}\right)$ & $109.562(3)$ \\
\hline Volume $\left(\AA^{3}\right)$ & $976.44(11)$ \\
\hline$Z$ & 2 \\
\hline Calculated density $\left(\mathrm{g} \cdot \mathrm{cm}^{-3}\right)$ & 1.219 \\
\hline Absorption coefficient $\left(\mathrm{mm}^{-1}\right)$ & 0.085 \\
\hline$F(000)$ & 384 \\
\hline$\theta$ range for data collection $\left(^{\circ}\right)$ & $2.89-21.16$ \\
\hline Index ranges & $-9<h<9 ;-13<k<13 ;-16<l<16$ \\
\hline Reflections collected & 19105 \\
\hline Independent reflections & 3754 \\
\hline Completeness to $2 \theta=51^{\circ}$ & $99.9 \%$ \\
\hline Refinement method & Full matrix LS on $\mathrm{F}^{2}$ \\
\hline Data/restrains/parameters & $2031 / 4 / 256$ \\
\hline Goodness-of-fit on $\mathrm{F}^{2}$ & 1.080 \\
\hline Final $R$ indices $[I>2 \sigma(I)]$ & $R=0.0582 ; \mathrm{w} R=0.1511$ \\
\hline$R$ indices (all data) & $R=0.1112 ; \mathrm{w} R=0.1774$ \\
\hline Largest diff. peak and hole & $-0.226 / 0.223$ \\
\hline
\end{tabular}

\subsection{Temperature-dependent $X$-ray powder diffraction measurements}

Powder diffractograms measured in function of temperature for several heating/cooling cycles show that polymorph II experiments a solid-solid transition to form I, between 130 and $140{ }^{\circ} \mathrm{C}$ (Figure $3 a$ ). Form I exhibits a powder pattern unambiguously different from that of polymorph II. The same powder pattern appears when cooling down from the melt (Figure $3 b$ ). Further cooling promotes a solid-solid transition from polymorph I to polymorph III'. Polymorph III' must be very similar to polymorph III whose crystal structure is being reported, since the simulated powder diffractogram from crystal data and the experimental diffractogram are very similar (Figure $3 c$ ). In a second heating cycle, polymorph III' changes into form I between $100-120^{\circ} \mathrm{C}$ (Figure $3 c$ ). A very small change in the powder pattern is seen around $50^{\circ} \mathrm{C}$, which may correspond to a small reorientation of the molecules within the crystal structure. 

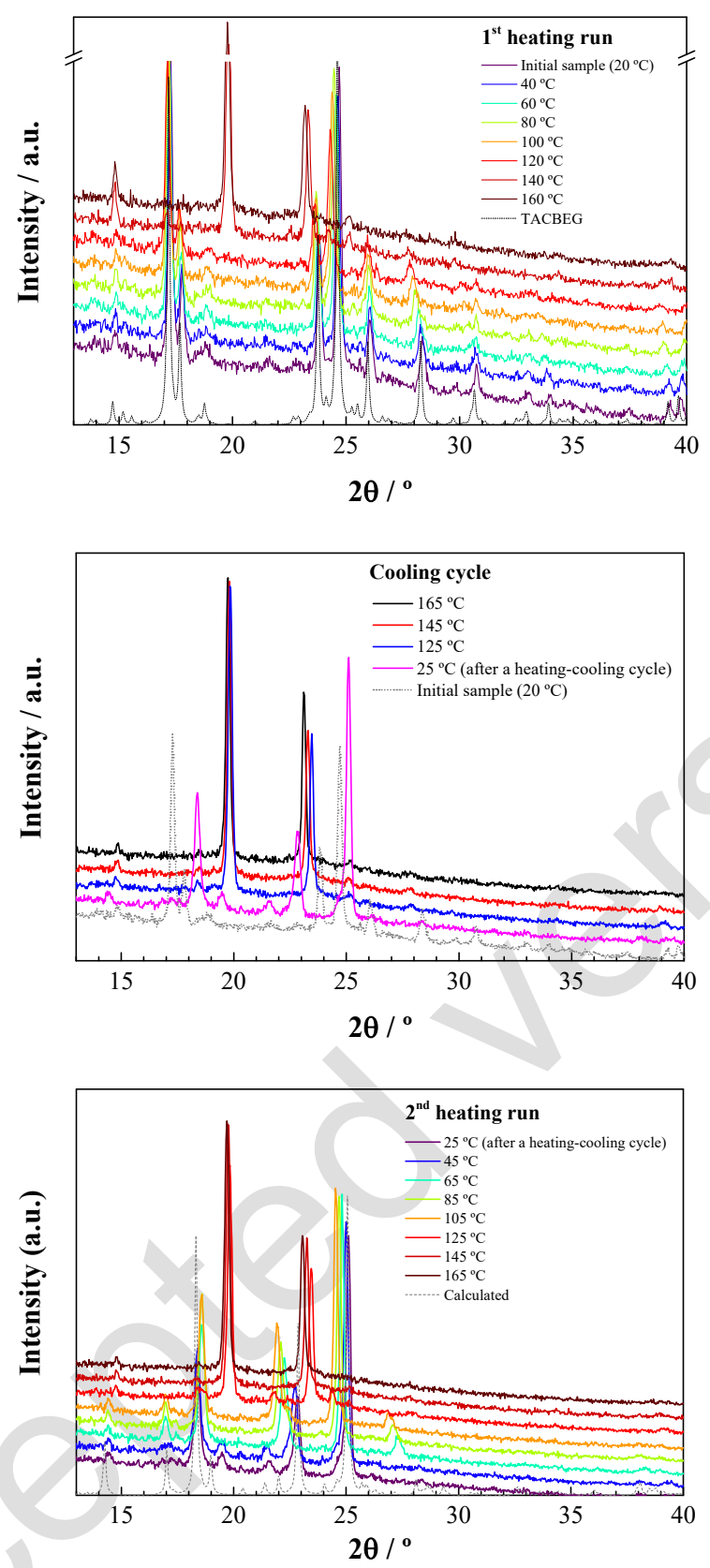

Figure 3. (a) Experimental X-ray powder diffraction patterns for the first heating run in the $20^{\circ} \mathrm{C}$ to $160^{\circ} \mathrm{C}$ range and calculated pattern for the polymorph II (TACBEG, [18]); (b) experimental X-ray powder diffraction patterns during the first cooling run and for polymorph II (grey dashed line); (c) evolution of the experimental powder diffraction patterns with temperature in the second heating run. The calculated pattern for the polymorph III (grey dashed line) is also shown for comparison purposes. An offset has been added in all subplots for clarity reasons.

\subsubsection{Evolution of unit cell parameters with temperature from Rietveld refinement for polymorph II}

The evolution of the powder pattern of polymorph II was followed with temperature and the usual displacement towards lower theta angles of the peak position could be observed, corresponding to a dilatation of the unit cell dimensions (Figure 4). However, since the peak displacement was not homogeneous, a full pattern analysis, using FullProf [19, 20], was performed to retrieve the unit cell parameters as a function of temperature (Figure 5). These data were then used to calculate the thermal expansivity tensor using PASCal [21]. 


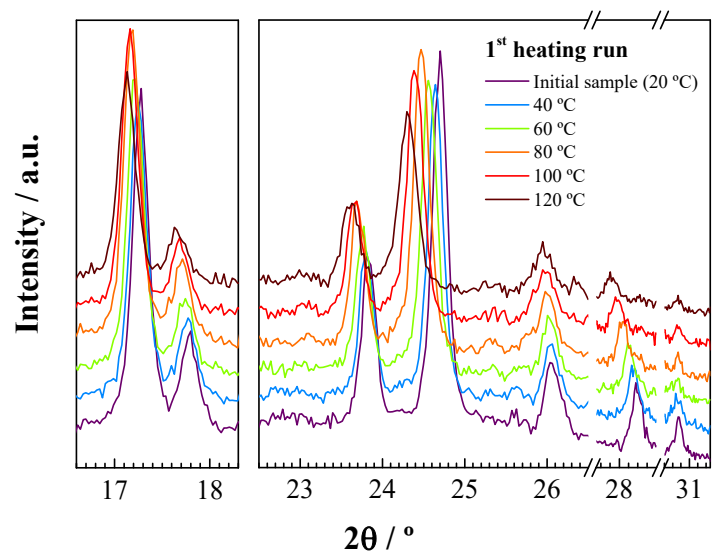

Figure 4. Detail of the peak position evolution with temperature during the first heating run for polymorph II.

Bulk expansitivities, $\alpha_{i}$, were calculated for a set of orthogonal axes, the principal axes, for which expansion or contraction describes the fundamental mechanical response of the system. For a monoclinic system the principal axes do not coincide with the cell axes.

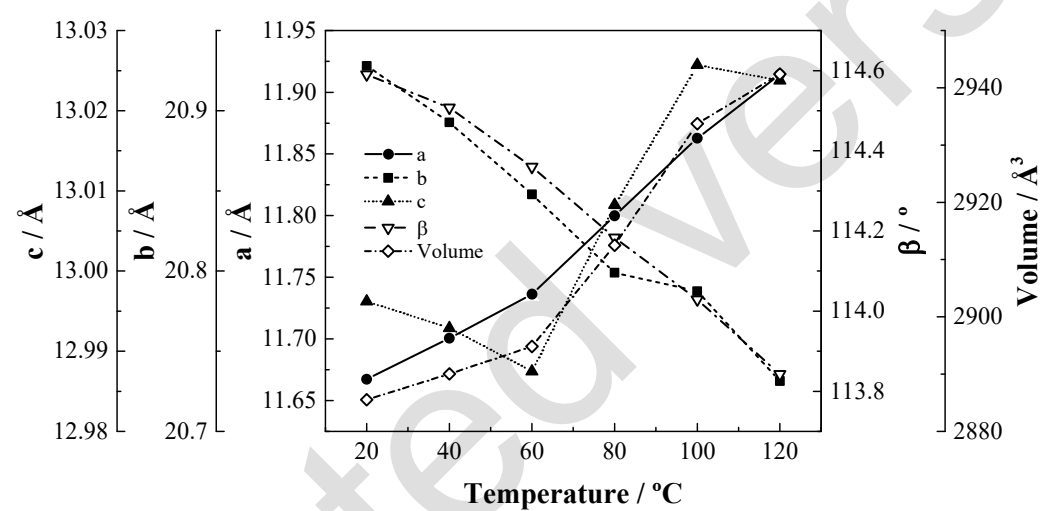

Figure 5. Rietveld-refinement resulting unit cell parameters at different temperatures for polymorph II (during the first heating run).

Molecules in polymorph II are assembled in chains, through H-bonds, that run along the [111] and [1111] directions related by the $2_{1}$ axis (Figure 6). The expansivity indicatrix points to a contraction along the $b$ axis and an expansion along the [201] direction (Table 2), which indicates that the temperature effect changes more the relative orientation of the chains than the distances within the chains, since the latter would affect all axis equally (Figure 7). 

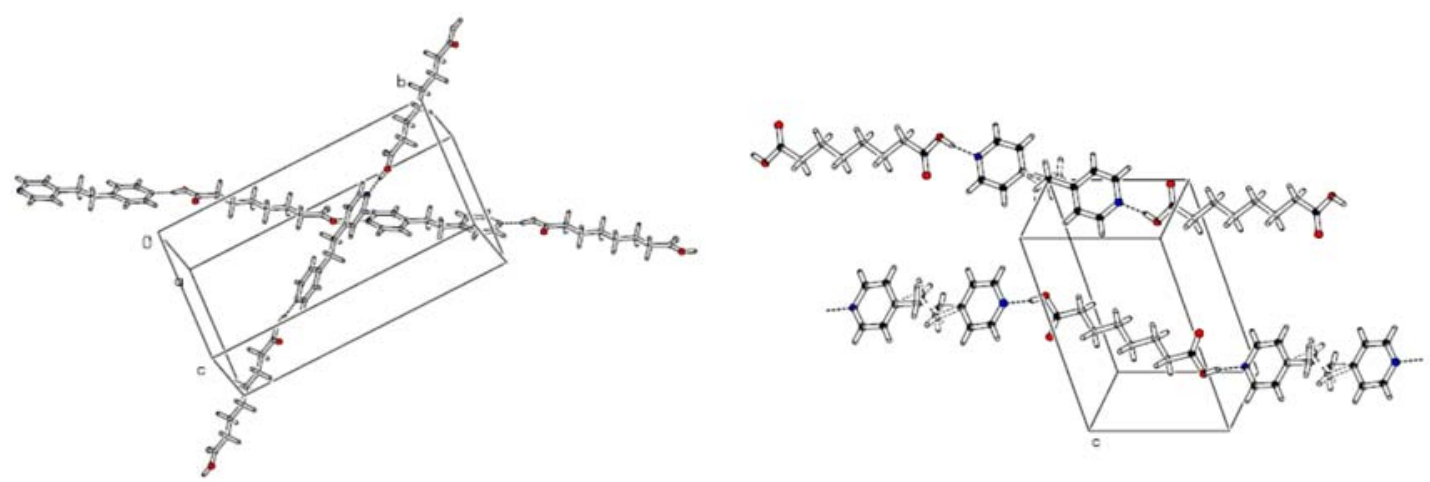

Figure 6. Left: Selected chains in the crystal structure of polymorph II showing that they follow oblique lines. Right: Selected chains in the crystal structure of polymorph III showing that they follow parallel lines.

Table 2. Principal coefficients of thermal expansion and corresponding principal axes determined for polymorph II.

\begin{tabular}{cccccc}
\hline & & \multicolumn{2}{c}{ Component of $\mathbf{x}_{i}$ along the crystallographic axes } & \\
\cline { 3 - 4 } Principal axis, $i$ & $\alpha_{i}\left(\mathrm{MK}^{-1}\right)$ & $a$ & $b$ & $c$ & Approximate axis \\
\hline 1 & $-92(3)$ & 0.0000 & -1.0000 & 0.0000 & {$[0 \overline{1} 0]$} \\
2 & $+26(6)$ & -0.1099 & -0.0000 & 0.9939 & {$[001]$} \\
3 & $+283(13)$ & 0.9138 & -0.0000 & 0.4061 & {$[201]$} \\
\hline
\end{tabular}

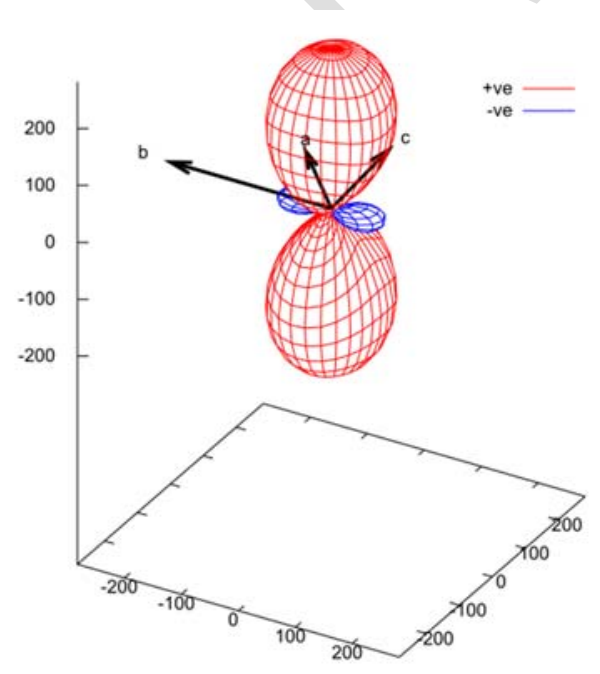

Figure 7. Plot of the expansivity indicatrices along the principal axes calculated as $\alpha_{l}=(1 / l) \cdot(\delta l / \delta t) \cdot P$ with PASCal.

\subsection{Vibrational characterization}

In Figure 8 and Table 3 the infrared spectra of suberic acid (SA), 1,2-bis(4-pyridyl)ethane (bPE) and of the polymorphic forms II and III of SA:bPE co-crystal are presented. The modifications observed in the infrared spectrum of SA:bPE co-crystal relative to the original compounds provide evidence that a new hydrogen-bond network was established. Two broad bands with characteristic maxima centred at approximately 2500 and $1910 \mathrm{~cm}^{-1}$ were observed which are attributed to adducts containing carboxylic acid $\mathrm{OH}^{\cdots} \mathrm{N}$ aromatic hydrogen bonds [22-26]. This feature is usually assigned to Fermi resonance of 
$\mathrm{OH}$ stretching and overtones of bending modes in $\mathrm{OH}^{\cdots} \mathrm{N}$ complexes [23]. The $v(\mathrm{C}=\mathrm{O})$ stretching band at $1685 \mathrm{~cm}^{-1}$ in SA, typical of dimer formation in carboxylic acids [27], appeared in the SA:bPE spectrum at $1694 \mathrm{~cm}^{-1}$ (form III) and at $1699 \mathrm{~cm}^{-1}$ (form II). The bands at $1454 \mathrm{~cm}^{-1}$ and $992 \mathrm{~cm}^{-1}$ of bPE (assigned to ring breathing [28]) were missing in the SA:bPE spectrum and a new band appeared at $490 \mathrm{~cm}^{-1}$.

In the infrared spectra of both co-crystal polymorphs, small differences were observed: the pattern of the bands between 2800 and $3000 \mathrm{~cm}^{-1}$ was clearly different; the $v_{\mathrm{s}}(\mathrm{C}=\mathrm{O})$ stretching bands at 1694 $\mathrm{cm}^{-1}$ (form III) and $1699 \mathrm{~cm}^{-1}$ (form II); the bands at $1465 \mathrm{~cm}^{-1}$ and $1066 \mathrm{~cm}^{-1}$ in form II appeared at $1469 \mathrm{~cm}^{-1}$ and $1058 \mathrm{~cm}^{-1}$ in form III, respectively. The slight differences observed in the infrared spectra of both co-crystal polymorphs were expected since the hydrogen-bond networks are similar.

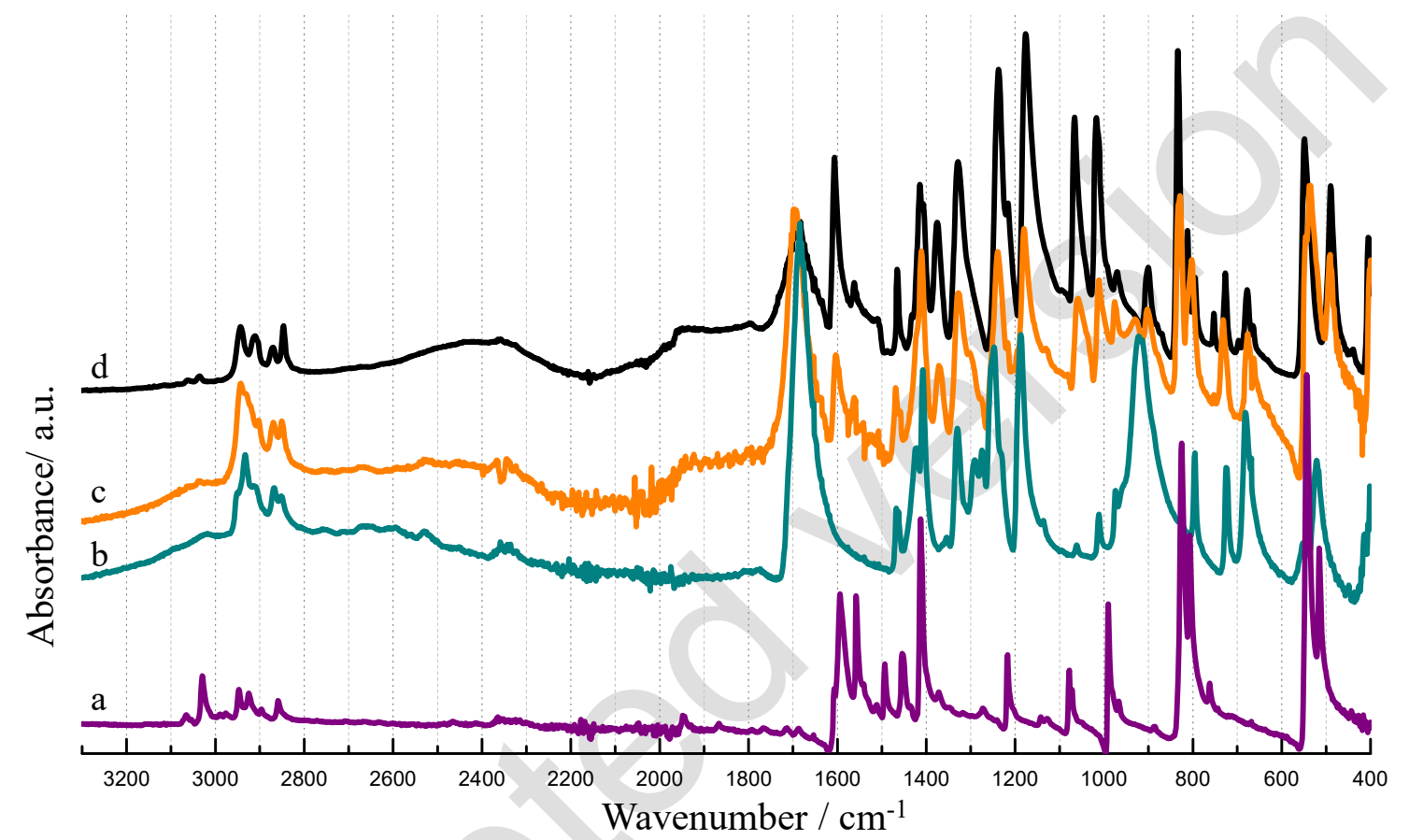

Figure 8. ATR-FTIR spectra of: (a) 1,2-bis(4-pyridyl)ethane, (b) suberic acid, (c) polymorph III co-crystal, and (d) polymorph II co-crystal.

Table 3. Comparison between the vibrational spectra of the two co-crystal polymorphs and their starting products.

\begin{tabular}{ccccc}
\hline Form III & Form II & SA & bPE & Assignment [22-29] \\
\hline $3035 ; 3062$ & $3035 ; 3062$ & - & $3030 ; 3065$ & $v(\mathrm{C}-\mathrm{H})$ aromatic \\
\hline & & - & $2925 ; 2947$ & $v\left(\mathrm{CH}_{2}\right)$ as \\
\hline & & - & 2859 & $v\left(\mathrm{CH}_{2}\right) \mathrm{s}$ \\
\hline $2943 ; 2902$ & $2943 ; 2869$ & $2950 ; 2932$ & & overlapping \\
$2870 ; 2850$ & $2910 ; 2847$ & $2915 ; 2868 ; 2851$ & & $v(\mathrm{C}-\mathrm{H})$ and $v(\mathrm{O}-\mathrm{H})$ \\
\hline ca. 2500 & ca. 2500 & & & $v(\mathrm{O}-\mathrm{H}) \cdots \mathrm{N}(\text { aromatic })^{*}$ \\
\hline ca. 1900 & ca. 1900 & & & $v(\mathrm{O}-\mathrm{H}) \cdots \mathrm{N}(\text { aromatic })^{*}$ \\
\hline 1694 & 1699 & 1685 & & $v(\mathrm{C}=\mathrm{O})$ \\
\hline $1604 ; 1561$ & $1606 ; 1562$ & & $1593 ; 15581493 ; 1412$ & In plane ring vibration \\
\hline 1465 & 1469 & 1467 & & $\delta\left(\mathrm{CH}_{2}\right)$ \\
\hline 1066 & 1058 & 1061 & $1078 ; 1072$ & $\omega\left(\mathrm{CH}_{2}\right), \delta(\mathrm{C}-\mathrm{O})$ \\
\hline 829 & 833 & & 992 & ring breathing \\
\hline
\end{tabular}

$\nu$, stretching $; \delta$, bending; $\omega$, wagging; $\tau$, torsion; as, asymmetric; s, symmetric

* assigned to Fermi resonance of $\mathrm{OH}$ stretching and overtones of bending modes in $\mathrm{OH} \cdots \mathrm{N}$ complexes [23] 


\subsection{Thermal analysis}

Figure $9(a)$ to $(d)$ present typical DSC curves obtained for the solid prepared by grinding, polymorph II, in two heating/cooling cycles. The DSC heating curves of suberic acid and 1,2-bis(4-pyridyl)ethane are also shown for comparison purposes in Figure $9(e)$ and $(f)$, respectively. In the first heating run of form II (see Figure $9(a)$ ) two endothermic transitions were identified: a solid-solid transition of form II to form I (confirmed by XRPD), at $T_{\operatorname{tr}(I I \rightarrow I)}=(129.8 \pm 0.7)^{\circ} \mathrm{C}$ with $\Delta_{\operatorname{tr}(I I \rightarrow I)} H=(29.6 \pm 0.6) \mathrm{kJ} \cdot \mathrm{mol}^{-1}$, followed by fusion of polymorph I at $T_{\text {fus,I }}=(180.5 \pm 0.2)^{\circ} \mathrm{C}$ with $\Delta_{\text {fus, }, ~} H=(50 \pm 1) \mathrm{kJ} \cdot \mathrm{mol}^{-1}$, which are in agreement with the literature [18]. These transitions were also observed by PLTM, Figure $10(a)$. Upon cooling the melt, two exothermic transitions were identified both by DSC and PLTM (see Figure $9(b)$ and Figure $10(b)$, respectively). The melt crystallization into polymorph $\mathrm{I}$, at $\beta=10^{\circ} \mathrm{C} / \mathrm{min}$, occurred at $T_{\text {cryst(L } \rightarrow \mathrm{l})}=(175.7 \pm 0.8){ }^{\circ} \mathrm{C}$ with $\Delta_{\text {cryst }(\mathrm{L} \rightarrow \mathrm{I})} H=(-45 \pm 2) \mathrm{kJ} \cdot \mathrm{mol}^{-1}$, followed by a solid-solid transition to form III' (confirmed by XRPD) at $T_{\operatorname{trs}(\mathrm{I} \rightarrow \mathrm{III})}=(114.4 \pm 0.3)^{\circ} \mathrm{C}$ with $\Delta_{\operatorname{trs}(\mathrm{I} \rightarrow \mathrm{III})} H=(-16.2 \pm$ $0.8) \mathrm{kJ} \cdot \mathrm{mol}^{-1}$. In the second heating run, Figure $9(c)$, the pattern of the DSC curve was similar to that of the first heating run, but the solid-solid transition occurred at a lower temperature, $T_{\operatorname{tr}(\mathrm{III} \rightarrow \mathrm{I})}=(119.5$ $\pm 0.3){ }^{\circ} \mathrm{C}$ with a smaller enthalpy value, $\Delta_{\mathrm{trs}\left(I I I^{\prime} \rightarrow \mathrm{l}\right)} H=(15.9 \pm 0.8) \mathrm{kJ} \cdot \mathrm{mol}^{-1}$, followed by fusion of polymorph I. The slightly differences between the PLTM images at $117^{\circ} \mathrm{C}$ and $120^{\circ} \mathrm{C}$ confirmed the solid-solid transition, Figure $10(c)$. It is worth noting that in subsequent heating/cooling runs, curves with similar patterns to those of Figure $10(c)$ and $(d)$ were obtained. The registered thermal behaviour together with the XRPD results proved that the co-crystal is still obtained from melt cooling.

The unusually high enthalpy values of the solid-solid transitions, II $\rightarrow$ I and III' $\rightarrow$ I lead to the conclusion that form I has some degree of disorder (also corroborated by X-rays, since the diffractogram showed fewer Bragg peaks). Attending to the endothermic nature of both solid-solid transitions an enantiotropic relation is expected between forms II/I and III'/I, according to Burger and Ramberger rule [30-32]. For the solid-solid transition of form III' into form II an enthalpy value of $-14 \mathrm{~kJ} \cdot \mathrm{mol}^{-1}$ is expected if heat capacity differences were negligible, being form III' monotropic relatively to form II. From the thermal behaviour study of SA:bPE co-crystal forms (I, II, III'), the Gibbs energy-temperature diagram presented in Figure 11 may be envisaged.

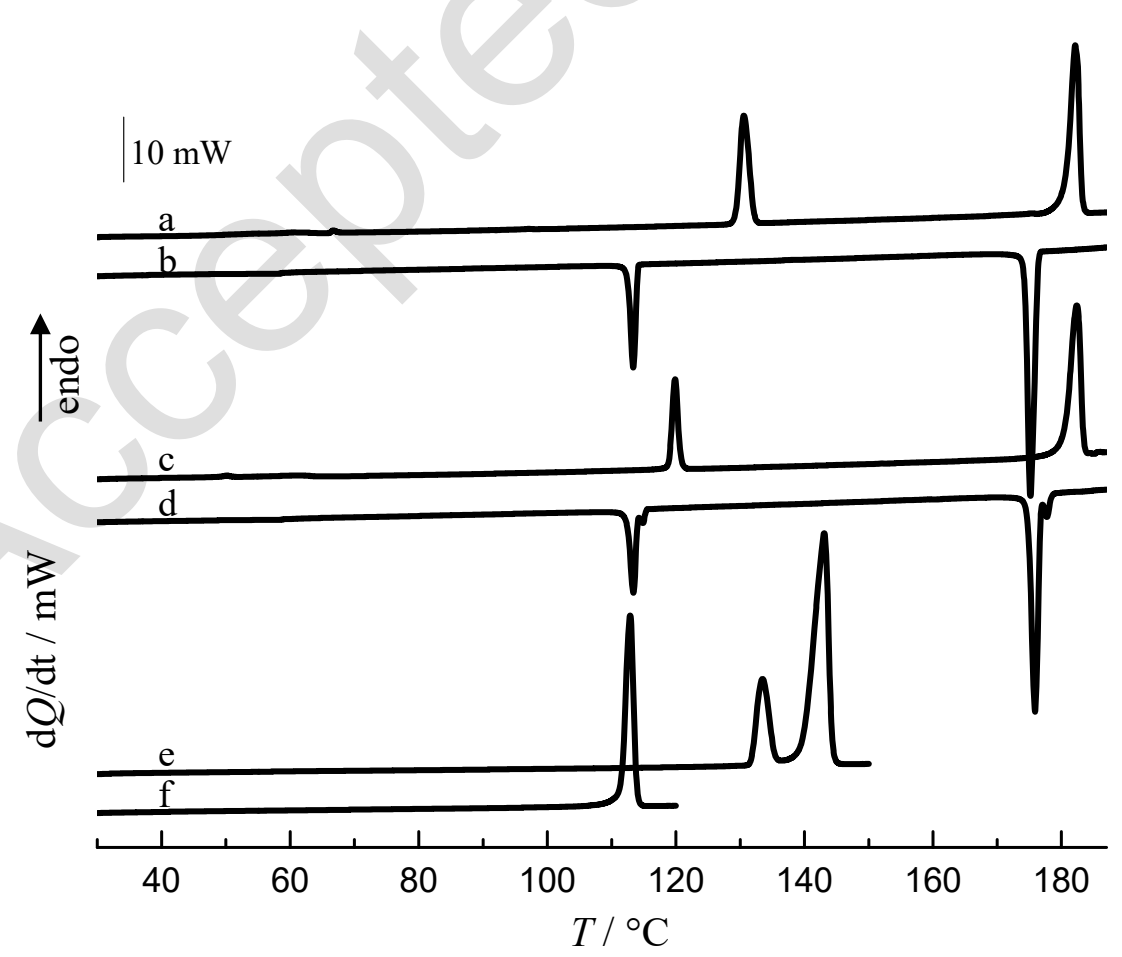

Figure 9. DSC curves. $(a)$ to $(d)$ correspond to the suberic acid:1,2-bis(4-pyridyl)ethane co-crystal: $(a)$ first heating run, $(b)$ melt cooling run, $(c)$ heating run of the solid obtained by melt cooling, $(d)$ second melt cooling run; (e) suberic acid heating run; $(f)$ 1,2-bis(4-pyridyl)ethane heating run. $\beta=10^{\circ} \mathrm{C} / \mathrm{min}$ in all cases. 
(a)
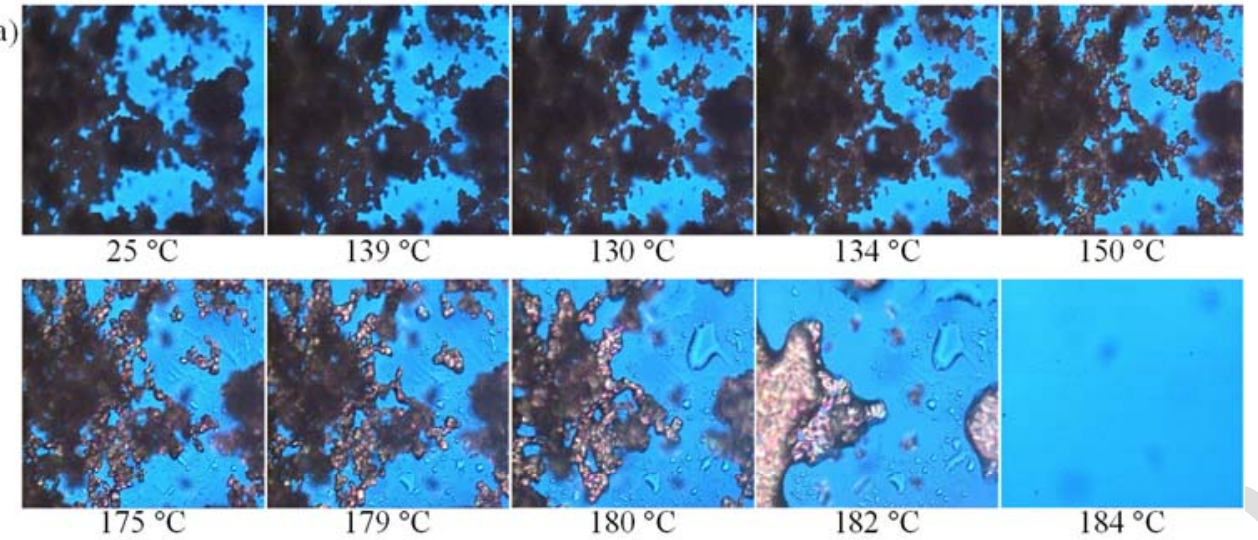

(b)
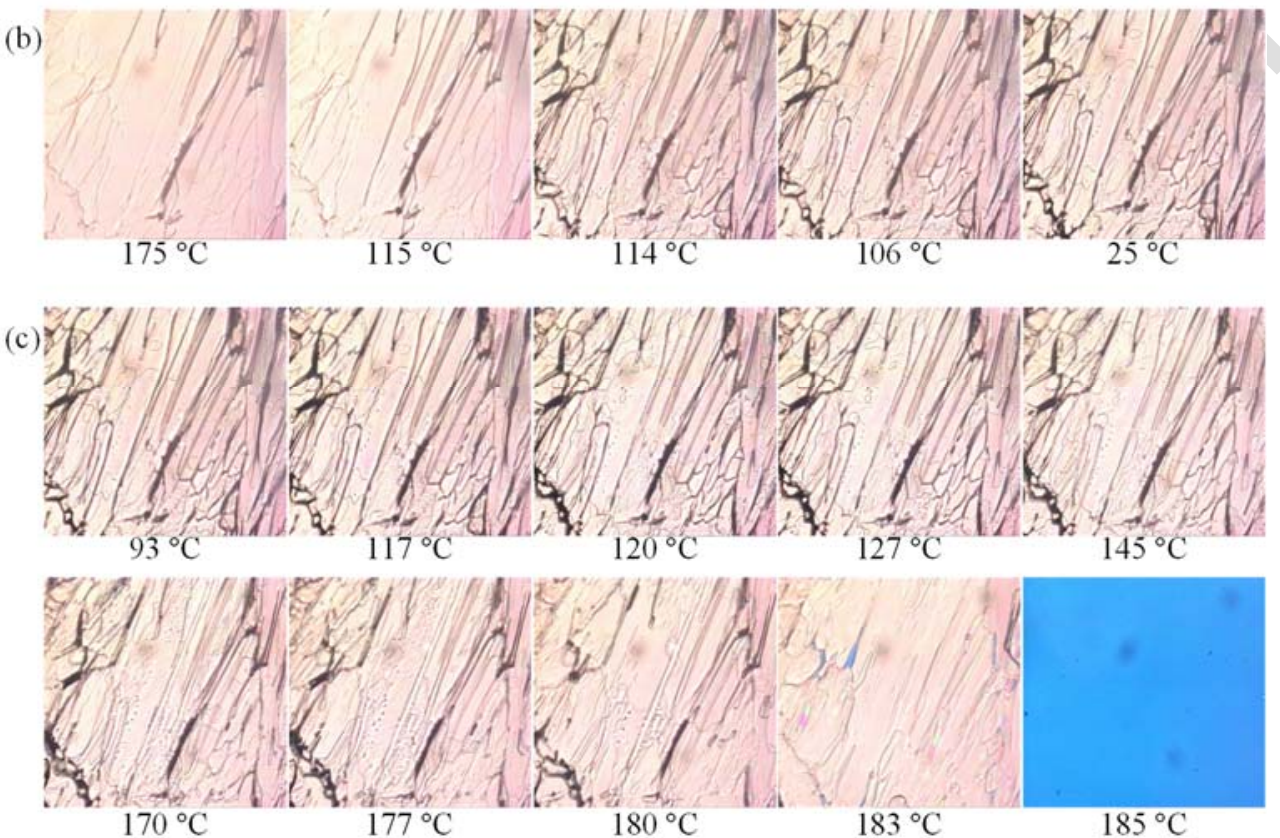

Figure 10. PLTM analysis of the suberic acid:1,2-bis(4-pyridyl)ethane co-crystal in the 25 to $185{ }^{\circ} \mathrm{C}$ range (second heating cycle). $\beta=10^{\circ} \mathrm{C} / \mathrm{min}$; magnification $200 \times$. 


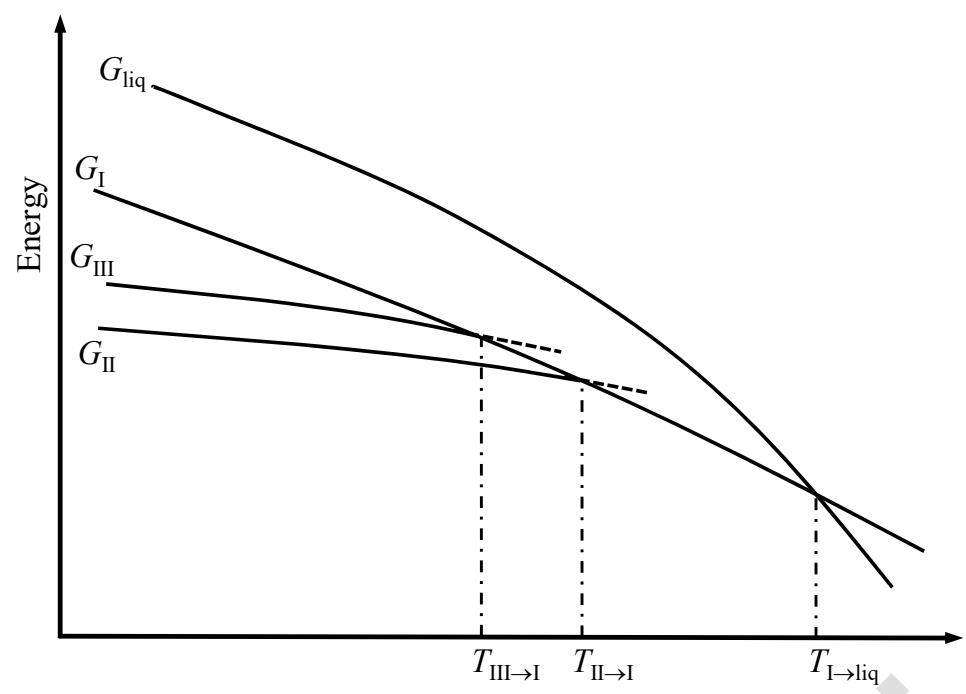

Figure 11. Energy/temperature diagram of the crystalline forms (I, II, III') of suberic acid:1,2-bis(4pyridyl)ethane co-crystal: $G$, free energy; $T$, transition temperature; liq, liquid.

\section{Conclusions}

The thermodynamic relationship between the two polymorphs II/I and III'/I of co-crystal SA:bPE was determined to be of enantiotropic nature while form III' was monotropic relatively to form II. Polymorphs II and III showed similar molecular configurations and similar hydrogen bond networks differing in the packing of the H-bonded chains. Increasing the temperature on polymorph II promoted a change in the relative orientation of the chains. With this study, new structural data on a packing polymorph is provided, along with the conditions for gradual transformations between the different identified forms. Further work on the crystallization of some of the remaining forms is under way so that full structural data can be available, with a view to optimizing crystal structure prediction.

\section{Acknowledgments}

This work was supported by FEDER/QREN/COMPETE-FCT through project PestOE/QUI/UI0312/2014 (Coimbra Chemistry Centre) and by FCT through project UID/FIS/04564/2016. M.S. thanks FCT for providing her grant under the doctoral programme ChemMat. S.F. acknowledges the support by the Erasmus mobility programme. P.M-R would like to thank Santander Universidades for its financial support through the "Becas Iberoamérica Jóvenes Profesores e Investigadores, España 2016" scholarship program. Access to TAIL-UC facilities funder under QREN-Mais Centro Project ICT_2009_02_012_1890 is gratefully acknowledged.

\section{References}

[1] A.R. Oganov, Modern methods of crystal structure prediction, Wiley-VCH, Weinheim, Germany, 2011.

[2] A.J. Aguiar, J. Krc, A.W. Kinkel, J.C. Samyn, Effect of polymorphism on the absorption of chloramphenicol from chloramphenicol palmitate, J. Pharm. Sci. 56(7) (1967) 847-853.

[3] J.K. Pandit, S.K. Gupta, K.D. Gode, B. Mishra, Effect of crystal form on the oral absorption of phenylbutazone, Int. J. Pharm. 21(1) (1984) 129-132.

[4] S. Aitipamula, P.S. Chow, R.B.H. Tan, Polymorphism in cocrystals: a review and assessment of its significance, CrystEngComm 16(17) (2014) 3451.

[5] Y. Sugita, Polymorphism of l-glutamic acid crystals and inhibitory substance for $\beta$-transition in beet molasses, Agric. Biol. Chem. 52(12) (1988) 3081-3085. 
[6] J. Bernstein, Polymorphism in molecular crystals, Oxford University Press, OxfordClarendon Press ; New York, 2002.

[7] H.G. Brittain, Polymorphism in pharmaceutical solids, 2nd ed., Informa Healthcare, New York, 2009.

[8] R. Hilfiker, Polymorphism in the pharmaceutical industry, Wiley-VCH, Weinheim, 2006.

[9] M.K. Mishra, U. Ramamurty, G.R. Desiraju, Mechanical property design of molecular solids, Curr. Opin. Solid State Mater. Sci. 20(6) (2016) 361-370.

[10] K.M. Steed, J.W. Steed, Packing Problems: High Z' Crystal Structures and Their Relationship to Cocrystals, Inclusion Compounds, and Polymorphism, Chem. Rev. 115(8) (2015) 2895-2933.

[11] T.S. Thakur, R. Dubey, G.R. Desiraju, Crystal Structure and Prediction, Annu. Rev. Phys. Chem. 66(1) (2015) 21-42.

[12] G. Sheldrick, SADABS, University of Göttingen, Göttingen, Germany, 1996.

[13] G.M. Sheldrick, A short history of SHELX, Acta Crystallogr. Sect. A: Found. Crystallogr. 64(1) (2007) 112-122.

[14] A.L. Spek, Single-crystal structure validation with the program PLATON, J. Appl. Crystallogr. 36(1) (2003) 7-13.

[15] C.F. Macrae, P.R. Edgington, P. McCabe, E. Pidcock, G.P. Shields, R. Taylor, M. Towler, J. van de Streek, Mercury: visualization and analysis of crystal structures, J. Appl. Crystallogr. 39(3) (2006) 453-457.

[16] R. Sabbah, A. Xu-wu, J.S. Chickos, M.L.P. Leitão, M.V. Roux, L.A. Torres, Reference materials for calorimetry and differential thermal analysis, Thermochim. Acta 331(2) (1999) 93-204.

[17] G. Della Gatta, M.J. Richardson, S.M. Sarge, S. Stølen, Standards, calibration, and guidelines in microcalorimetry. Part 2. Calibration standards for differential scanning calorimetry* (IUPAC Technical Report), Pure Appl. Chem. 78(7) (2006).

[18] D. Braga, E. Dichiarante, G. Palladino, F. Grepioni, M.R. Chierotti, R. Gobetto, L. Pellegrino, Remarkable reversal of melting point alternation by co-crystallization, CrystEngComm 12(11) (2010) 3534.

[19] J. Rodríguez-Carvajal, Recent advances in magnetic structure determination by neutron powder diffraction, Physica B: Condensed Matter 192(1-2) (1993) 55-69.

[20] J. Rodríguez-Carvajal, Recent developments of the program FULLPROF, Commission on powder diffraction (IUCr) Newsletter 26 (2001) 12-19.

[21] M.J. Cliffe, A.L. Goodwin, PASCal: a principal axis strain calculator for thermal expansion and compressibility determination, J. Appl. Crystallogr. 45(6) (2012) 1321-1329.

[22] C.B. Aakeröy, D.J. Salmon, M.M. Smith, J. Desper, Cyanophenyloximes: reliable and versatile tools for hydrogen-bond directed supramolecular Synthesis of cocrystals, Crystal Growth \& Design 6(4) (2006) 1033-1042.

[23] J.P. Castaneda, G.S. Denisov, S.Y. Kucherov, V.M. Schreiber, A.V. Shurukhina, Infrared and $a b$ initio studies of hydrogen bonding and proton transfer in the complexes formed by pyrazoles, J. Mol. Struct. 660(1-3) (2003) 25-40.

[24] Y. Belabbes, A. Lautié, Vibrational study of oxalic acid - pyrazine hydrogen bonded adducts, Vib. Spectrosc 9(2) (1995) 131-137.

[25] C.S. Cassidy, L.A. Reinhardt, W.W. Cleland, P.A. Frey, Hydrogen bonding in complexes of carboxylic acids with 1-alkylimidazoles: steric and isotopic effects on low barrier hydrogen bonding, Journal of the Chemical Society, Perkin Transactions 2 (3) (1999) 635-642.

[26] D. Hadži, N. Kobilarov, Hydrogen bonding in some adducts of oxygen bases with acids. Part II. Infrared spectra of liquid adducts of carboxylic acids with sulphoxides, phosphine oxides, and other bases, J. Chem. Soc. A 0(0) (1966) 439-445.

[27] D.L. Pavia, G.M. Lampman, G.S. Kriz, Introduction to Spectroscopy, $5^{\text {th }}$ ed., Cengage Learning, Boston, MA, 2014.

[28] R. Aroca, P. Corio, J.C. Rubim, Surface enhanced vibrational spectroscopy of 1,2-Bis(4pyridyl)ethane, J. Braz. Chem. Soc. 7(6) (1996) 461-469.

[29] G. Sailakshmi, T. Mitra, S. Sinha, S. Chatterjee, A. Gnanamani, A.B. Mandal, Suberic Acid Acts as a Dissolving Agent as Well as a Crosslinker for Natural Polymers (Carbohydrate and Protein): A Detailed Discussion on the Chemistry Behind the Interaction, Journal of Macromolecular Science, Part A 49(8) (2012) 619-629. 
[30] A. Burger, R. Ramberger, On the polymorphism of pharmaceuticals and other molecular crystals. I, Mikrochim. Acta 72(3-4) (1979) 259-271.

[31] A. Burger, R. Ramberger, On the polymorphism of pharmaceuticals and other molecular crystals. II, Mikrochim. Acta 72(3-4) (1979) 273-316.

[32] D.D. Wirth, G.A. Stephenson, Purification of Dirithromycin. Impurity reduction and polymorph manipulation, Organic Process Research \& Development 1(1) (1997) 55-60. 